\title{
Experimental Modeling of the Explosion Mechanism of Basaltic Magmas
}

\author{
A. Yu. Ozerov \\ Institute of Volcanology and Seismology, Far East Division, Russian Academy of Sciences, \\ bul'v. Piipa 9, Petropavlosk-Kamchatskii, 683006 Russia \\ e-mail: ozerov@ozerov.ru \\ Received November 10, 2008
}

\begin{abstract}
Processes in the feeders of basaltic volcanoes during Strombolian-type eruptions were examined with the use of a complex apparatus for modeling basaltic eruptions (CAMBE), which was designed and manufactured by the authors for this purpose. The experimental setup consists of modeling and registering units and has a height of $18 \mathrm{~m}$. It was designed with regard for the geometric dimensions of a natural feeding volcanic system: the ratio of the inner diameter of the feeder to its height is approximately $1: 1000$. CAMBE was the first modeling equipment making possible passing a flow of gas-saturated liquid through the conduit, which allowed us to study the nucleation of gas bubbles, their growth, coalescence, transformations of the gas structures, and the kinetics of the gas phase. The experiments were carried out in a manner that made it possible to eliminate effects of structural barriers and fluctuations in the liquid flow velocity. As a result of the experiments, a new (previously unknown) regime in the flow of two-phase systems through a vertical conduit was discovered: the cluster regime, which is characterized by systematically alternating dense accumulations of gas bubbles (bubble clusters) and liquid devoid of a free gas phase. It is demonstrated that the liquid, bubbly, cluster, and slug regimes systematically grade into one another and are polymorphic modifications of gas-saturated liquids moving through vertical conduits. Our data led us to propose a new model for the gas-hydrodynamic movement of magmatic melt through the conduit of a basaltic volcano: depending on the gas-hydrodynamic regime in the volcanic vent, various types of eruptive activity (up to explosions) may take place. The analyses of basaltic magma explosions allowed us to describe them from a new standpoint and recognize the following four major modes of their manifestations at the surface: (1) weak ash explosions early during the cluster regime, (2) strong ash explosions during the mature cluster regime, (3) bomb explosions during the slug regime, (4) bomb grading to ash explosions during the slug regime associated with trains of small bubbles.
\end{abstract}

DOI: $10.1134 / \mathrm{S} 0869591109070029$

\section{INTRODUCTION}

Our research was centered on the Strombolian type of volcanic activity, which is the most common at basaltic volcanoes (Luchitskii, 1971; Vlodavets, 1984).

An explosion of the Strombolian type is a powerful, drastic, an usually unexpected event. Explosions of this type occur in the course of summit, auxiliary, and lateral eruptions. Incandescent volcanic bombs are ejected in the form of a fan or a vertical plume as high as tens to hundreds of meters (Fig. 1a), and ash clouds reach altitudes from a few hundreds to one thousand meters and are then carried by wind as eruption blankets for tens of kilometers. The explosions are usually brief, last for a few to a few dozen seconds, and are separated by quiescence periods, which range from a few to tens of minutes or, occasionally, even a few hours and are followed by other eruptions (Fig. 1b). Such discrete eruptions may continue at volcanoes for weeks, months, and even years or occasionally last as long as a few centuries. Explosive activity is sometimes accompanied by eruptions of lava flows. An explosion of average size erupts 30-50 tons of magmatic products, and powerful explosions erupt as much as 250-1000 tons of material (Fig. 1a). Strombolian explosions often generate seismic waves.

Since there is still no unambiguous explanation of either the mechanisms of Strombolian-type eruptions or the reasons for their diversity, we carried out an experimental research that enabled us to understand the mechanism of Strombolian activity. In 2002 we launched laboratory experiments with two-phase mixtures. Over the next five years, nine gas-hydrodynamic experimental setups were designed and manufactured, and eventually a complex apparatus for modeling basaltic eruptions (CAMBE) was built, and a set of experiments was conducted on it. The experimental setup was designed with regard for the geometric parameters of the natural feeding systems of Klyuchevskoi volcano.

Our studies were centered mainly on elucidating why the discrete regime of basaltic magma eruptions develops in the form of rhythmical eruptions. The main method of our research was the experimental study of the kinetics of two-phase mixtures in vertical conduits 


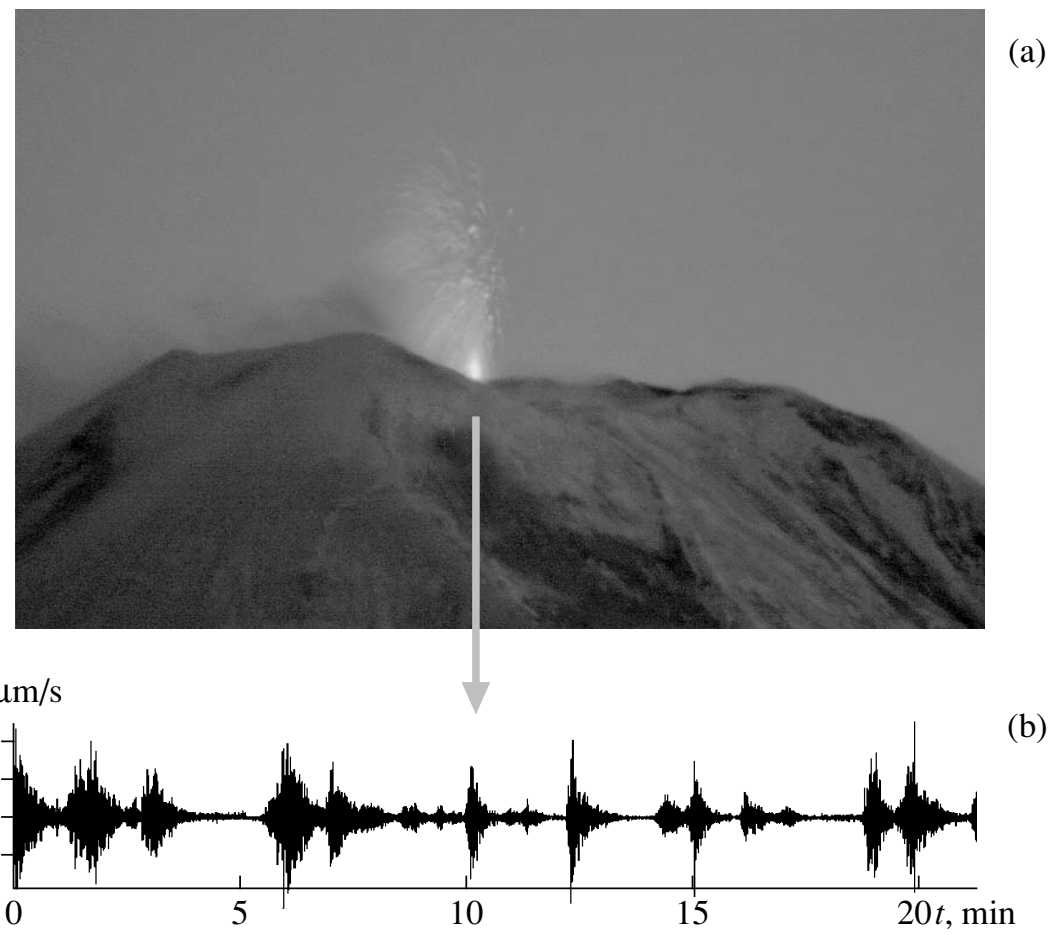

(a)

(b)

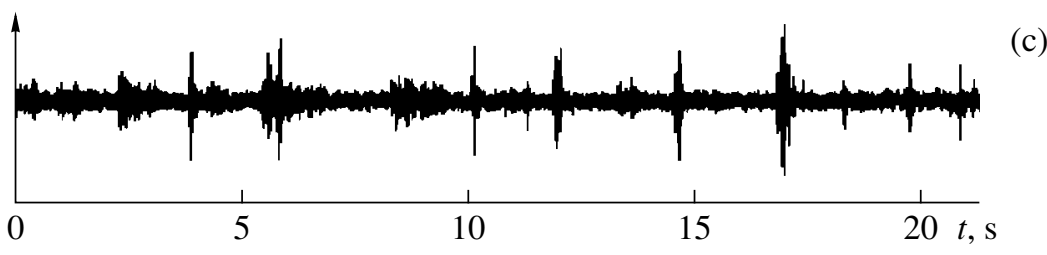

Fig. 1. Comparison of the explosive activity of Klyuchevskoi volcano with manifestations of the slug regime at the surface as modeled on the CAMBE experimental setup.

(a) Explosion in the summit crater of Klyuchevskoi volcano on March 23, 2007 (8 hours 14 min 30 s GMT). View from the north. The maximum height of bomb ejections was $230 \mathrm{~m}$; the volume of the ejected material was approximately 500 tons (estimated minimum value). The photo was taken at a distance of $32 \mathrm{~km}$ by Yu.V. Demyanchuk.

(b) Fragment of a seismic record for the explosive activity of the summit crater of Klyuchevskoi volcano on March 23, 2007 (8 hours $04 \mathrm{~min} 30 \mathrm{~s}$ GMT) as registered at the Loginov seismological station at a distance of $12 \mathrm{~km}$ from the crater. The arrow indicates the seismic event that accompanied the explosion.

(c) Fragment of an acoustic record of bursts of the slug regime of the model liquid at the upper end of the CAMBE experimental column. The registering microphone is mounted at a distance of $20 \mathrm{~cm}$ from the upper end of the hose.

(starting with the nucleation of the first gas bubbles until the development of mature stable gas structures) and the comparison of the results with data obtained on real volcanic events. The experimental pipe enabled us to model processes in a magmatic conduit and (at the top end of the pipe) eruptive processes in a volcanic vent.

When a gas-saturated liquid moved along the vertical pipe during the experiment, we studied the structural restyling of the model liquid. We documented the following four successively developing gas-hydrodynamic regimes: liquid, bubbly, cluster, and slug. Much attention was paid to the previously unknown regime that occurs between the bubbly and slug regimes. This newly discovered morphologically persistent gashydrodynamic regime is referred to as the cluster regime. The mechanism generating the clusters is described below.

In the course of our experiments, we continuously recorded the acoustic signal at the top end of the pipe, where the model liquid outpoured. The acoustic record of the slug regime was compared with the seismographic record during an eruption of Klyuchevskoi volcano.

Based on data on the energy of powerful discrete volcanic eruptions, the viscosity of basalt magmas, and our experimental results, we described the possible scenarios of basaltic magma explosions and classified the types of volcanic activity depending on the type of the gas-hydrodynamic regime. 
(a)

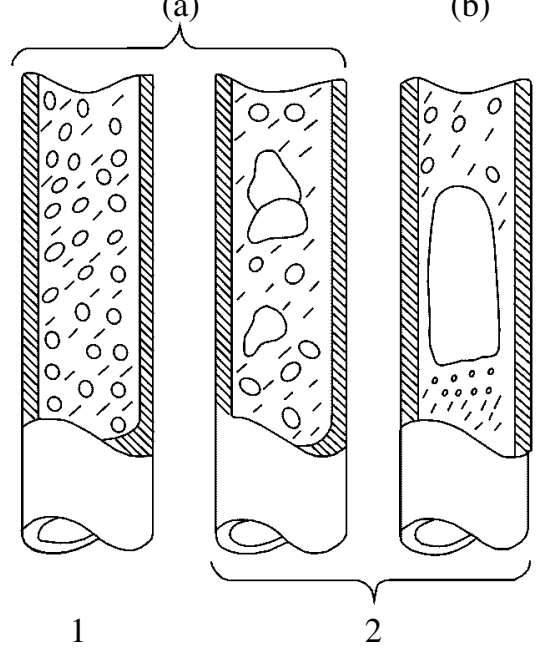

(c)

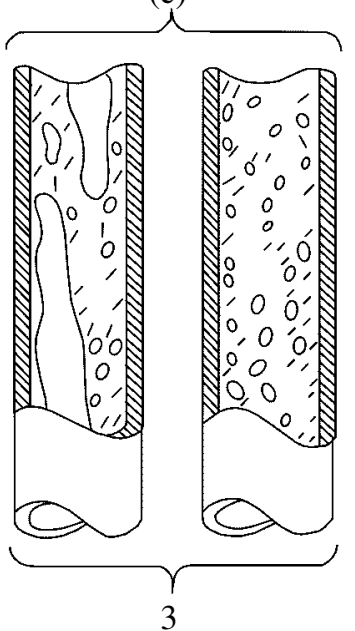

(d)

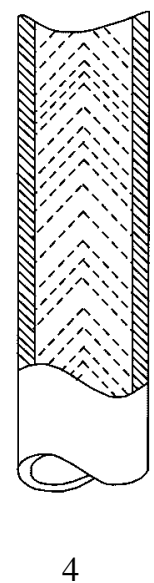

Fig. 2. Correlation between the flow regimes of two-phase mixtures and types of eruptions (Drozdin, 1980). (a-d) Flow regimes of two-phase mixtures: (a) bubbly, (b) slug, (c) dispersed, (d) disperse; (1-4) types of eruptions: (1) Hawaiian, (2) Strombolian, (III) Etna-Vesuvian, (IV) Vulcanian.

\section{REVIEW OF THE PREEXISTING PUBLISHED MATERIALS}

The late 20th century witnessed the development of a common approach to understanding processes in the upper parts of the feeding systems of basaltic volcanoes on the basis of hydrodynamic laws for two-phase gasliquid systems. For example, processes in vertical conduits were described with the use of the following five flow regimes of two-phase mixtures: bubbly, slug, foamy, dispersed, and disperse (Kozlov, 1955). Later a chart of these flow regimes was published with reference to gas-liquid flows in vertical conduits (Sorokin, 1963). Results of the fundamental studies of flow regimes of two-phase mixtures were presented in the monographs (Wallis, 1969; Kutateladze and Nakoryakov, 1984).

A number of papers published in the 1960s presented attempts to explain natural basaltic explosions from the standpoint of hydrodynamics. Rittmann (1960) was among the first to discuss the possibility for bubbles entrained in a magmatic column to grouping into schlieren. The direct comparison of the flow regimes of two-phase mixtures was first made by Droznin (1969), whose later studies were vividly illustrated (Droznin, 1980) (Fig. 2). Starting at that time, his materials were compiled (with minor modifications) in all volcanological publications devoted to eruption mechanisms (Carrigan et al., 1992; Jaupart, 2000; Vergniolle, Mangan, 2000; Privitera et al., 2003). A comprehensive review and analysis of publications on the application of hydrodynamic laws to natural processes is presented in (Sparks, 1978).

With regard for the aforesaid, it is worth mentioning that natural manifestations of the dynamics of basaltic eruptions can be fairly realistically described by hydro- dynamic concepts concerning the movement of twophase mixtures along vertical pipes. However, the transition from the bubbly to slug regimes is uncertain so far. It is known that a pressure decrease in a gas-saturated liquid results in that the dissolved gas starts to form a free gas phase, i.e., gas bubbles are generated. Also, each individual large bubble of the slug type is known to generate an explosion-like burst on its surface. However, it remains unclear as to why do the bubbles merge into larger gas structures, in spite of the fact that bubble coalescence requires significant work to be done on their mutual approach and compression. The nature of the driving forces of this process is also unknown. Neither of these problems was solved within the scope of known gas-hydrodynamic data.

In order to solve these problems, experiments were conducted along the following three avenues. First, searches for unknown phenomena in gas-liquid interactions were carried out, and then, if these phenomena were identified, they were taken into account in the concept developed for the action of the feeding volcanic system. Second, structural changes in the two-phase flow during its passage from a large "magmatic chamber" into a narrow "magmatic feeder" were modeled. Finally, the evolution of the two-phase flow in a long and narrow vertical pipe was studied as a model of a magmatic feeder.

The first avenue was pursued in the experimental studies (Manga and Stone, 1994; Manga, 1996). It was demonstrated that the ascending bubbles can merge/coalesce and foamy structures and can be segregated in a stationary liquid. In spite of the elegance of these studies, it should be mentioned that the experiments on which all further constructions were based were made under the following ideal conditions: (1) in a stationary liquid; (2) within small vertical intervals; 
and (3) the marginal (near the walls) effects were ignored. This largely obscured the general picture of the evolution of a highly dynamic two-phase flow corresponding to a magmatic melt ascending to the surface.

The second avenue was followed by Vergniolle and Jaupart (1986, 1990), who managed to develop an interdisciplinary theory for discrete explosion/gushing, a synthesis of volcanology and gas hydrodynamics. A principal assumption of this model, which explains the reasons for explosion/gushing, is the occurrence of a large intermediate magma chamber connected with the surface by a thin conduit, with the diameter of the chamber being hundreds to thousands times greater than the diameter of the conduit. The flux of gas bubbles ascending thought the liquid reaches the roof of the chamber, the bubbles accumulate beneath this roof, are transformed into foam, and enter the feeder in discrete portions. The appearance of portions of gas bubbles in the vent eventually results in an explosion or outpouring episode. Hence, Vergniolle and Jaupart presume the necessary existence of a geometric structural barrier (the roof of the chamber) that works as an accumulator and batching mechanism of the gas phase. Many researchers tried to explain the discrete supply of material during volcanic eruptions using this model (Carrigan et al., 1992; Chouet et al., 1997; Delfa et al., 2001; Privitera et al., 2003).

This model is, however, inapplicable to Klyuchevskoi volcano, a typical and fairly thorough examined basaltic volcano. First, seismic and petrological evidence indicates that its plumbing system has no shallow-sitting magmatic chamber (Gorshkov, 1956; Firstov and Shirokov, 1971; Balesta et al., 1976; Gorel'chik, 1976; Utnasin et al., 1976; Gordeev et al., 1986; Fedotov, 1993, 2006; Fedotov et al., 1988; Ariskin et al., 1995; Ozerov, 2000; Ozerov et al., 1996, 1997; Khrenov et al., 2002; Lees et al., 2007). Second, the eruption dynamics of Klyuchevskii volcano was determined to show a number of persistently occurring periodicity groups that significantly differ from one another: $t_{1}=1 \mathrm{~min} 34 \mathrm{~s}, t_{2}=6 \mathrm{~min} 10 \mathrm{~s}, t_{3}=40 \mathrm{~min}$, $t_{4}=5 \mathrm{~h} 30 \mathrm{~min}$, and $t_{5}=36 \mathrm{~h}$ (Ozerov and Konov, 1988; Konov and Ozerov, 1988; Ozerov et al., 2007). Using the model proposed by Vergniolle and Jaupart and taking into account the periodicities in the eruption dynamics of the volcano, one has to suggest the presence of more than one chamber of significantly different size, with each of the chambers having its own conduit that being directly connected with the summit crater. These inconsistencies cannot be explained within the scope of known gas-hydrodynamic models of Vergniolle and Jaupart.

The author of this paper pursued the third avenue of research and examined gas-hydrodynamic effects that occur in long vertical pipes. The physics of the process was modeled on the CAMBE laboratory experimental setup, which was designed and manufactured for this research (Ozerov, 2007). This equipment allowed us to model the effects occurring in a vertical pipe during the flow of a gas-saturated liquid through it (but not merely to fragmentarily examine some regimes of two-phase mixtures, as was done in earlier studies). We also studied the character of manifestations of each individual regime at the top end of the pipe. The pipe made it possible to model process in a magmatic conduit and (at the upper end of the pipe) in the crater (vent) of a volcano.

\section{EQUIPMENT FOR MODELING BASALTIC ERUPTIONS}

The experimental setup was designed in a way that made it possible to take into account as much as possible parameters of the feeding systems of naturally occurring volcanoes (as exemplified by that of Klyuchevskoi volcano). Based on all available literature data, we selected the most typical parameters of its feeding system. We also tried to eliminate the effects of any and all possible structural and energetic barriers that could affect the character of material flow. Below we report the basic principles that were used by the author in designing the laboratory equipment (principles 1 through 10) and in conducting the experiments (principles 11 through 14):

(1) flux of magmatic melt through the feeding system (conduit) does not vary;

(2) the magmatic melt entering the lower end of the conduit is homogeneous, and its viscosity does not vary;

(3) the conduit is round or oval in cross section;

(4) the walls of the conduit are resilient and do not generate any vibrations able to induce drastic changes in the melt flow;

(5) the height of the conduit is hundreds to thousands of times greater than its diameter;

(6) magma ascends along the conduit vertically, and the character of the flow at the lower end of the conduit is definitely laminar;

(7) the melt entering the lower end of the conduit contains no free gas phase;

(8) when the melt ascends along they conduit, bubbles are formed (nucleation of bubbles) and then increase in size;

(9) the viscosity parameters of the melt is such that gas bubbles move through it much more rapidly that the liquid flows;

(10) the upper end of the conduit is not blocked by any clogs of solidified melt that can affect the behavior of the two-phase flux when it is poured out at the surface (the system is open);

(11) the homogeneous two-component model liquid (water with carbon dioxide dissolved in it) evolves into a two-phase system (liquid water and gaseous carbon dioxide), which makes our experiments significantly 
different from earlier experiments in homogeneous systems, in which a liquid and gas emulated different states of the same material (for example, water and vapor);

(12) we deliberately ignored the third component that is commonly contained in magmatic melts in the form of a crystalline phase because the percentage of this phase in basaltic melts is low (moreover, it is senseless to study more complex systems before examining all gas-liquid relations);

(13) our modeling was carried out for an eruption in a mature phase, when the magmatic conduit is formed; the effects related to preparatory phases and the end of the eruption were not considered;

(14) the experiments were conducted with a model liquid with a low gas content (under pressures up to 2 atm), at a temperature of approximately $20^{\circ} \mathrm{C}$; no regimes with great gas yields (ring, dispersed, and disperse) were studied.

The CAMBE experimental setup was assembled at the Institute of Volcanology and Seismology, Far East Division, Russian Academy of Sciences; its total height is $18 \mathrm{~m}$. CAMBE consists of two units: modeling and registering. The principal design of the equipment, its design calculations, manufacturing of parts, and assembling of the CAMBE setup were accomplished by the staff of the institute. The supervisor of the project was A.Yu. Ozerov, the engineers were A.V. Butkach, V.S. Shul'ga, and O.I. D'yachkova; the lathe and milling machine operator was S.F. Laktionov; consultations were provided by V.A. Droznin.

CAMBE was manufactured to study the mechanism of volcanic processes, and hence, for convenience of the further discussions of the experimental results, its parts are provisionally named by analogy with certain parts of a volcanic system.

The Modeling unit includes a reservoir for preparing a gas-saturated model liquid (magmatic chamber), a transparent hose (feeding conduit), and an aquarium for receiving the arriving model liquid (crater/vent) (Figs. 3a, 3b).

Chamber. In designing this component of the experimental setup, we tried to build an experimental analogue of a magmatic chamber from which a homogeneous liquid with dissolved gas is supplied to the feeder. The "chamber" is a thick-walled hermetically sealed reservoir (made of stainless steel) $2.3 \mathrm{~m}$ high and 3501 in volume. To saturate the liquid with gas, a perforated pipe with 50 holes is connected (welded) to the lower part of the reservoir. The pressure in the system is measured with a manometer in the upper part of the reservoir. The water column running along the reservoir throughout its whole height makes it possible to monitor the liquid level in the reservoir. A gas valve welded in the upper part of the reservoir serves for pumping an inert gas into the reservoir during the experiments; the inert gas serves as a pressing-out piston. Safety during the saturation of liquid with gas is ensured by an emergency relief valve. This part of the experimental setup is, in fact, a saturator (a device for dissolving gas in a liquid).

The experiments were carried out with one liquid (water) and two gases (carbon dioxide and nitrogen). Carbon dioxide $\left(\mathrm{CO}_{2}\right)$ is highly soluble in water $(11$ of water can dissolve up to $828 \mathrm{ml}$ of carbon dioxide at an experimental temperature of $20^{\circ} \mathrm{C}$ and a pressure of $1 \mathrm{~atm})$ and can be readily released as a free gaseous phase (Khamiot, 1991). Nitrogen $\left(\mathrm{N}_{2}\right)$ was used as a medium for expelling the model liquid from the reservoir. This gas is practically insoluble in water $(11$ of water can dissolve as little as $18 \mathrm{ml}$ of nitrogen at an experimental temperature of $20^{\circ} \mathrm{C}$ and a pressure of 1 atm) (Khamiot, 1991). Both gas tanks (for carbon dioxide and nitrogen) are equipped with gas pressure regulators to vary the gas flow.

Feeder/conduit. This part of the experimental setup is design for modeling processes in the feeding system of a volcano. A stainless steel pipe going from the lower part of the reservoir changes the axial direction to a vertical one, and the swan-neck of the pipe precludes the development of turbulence in the flow. The pipe is equipped with a ball valve for varying the flow of model liquid from the reservoir to the plastic hose.

The upper part of the steel pipe is connected with a transparent plastic hose $16600 \mathrm{~mm}$ long (high) $18 \mathrm{~mm}$ in inner diameter. The ratio of the working cross section (inner diameter) to the length (height) of the hose is approximately $1: 1000$, which is close to the analogous parameters of naturally occurring volcanic feeders.

A specialized bracing system makes it possible to fix the hose vertically. Ticks in the measuring tape that runs along the conduit are spaced $1 \mathrm{~mm}$ apart.

The pipe, ball valve, and hose have equal inner diameters. Along with the swan-neck of the pipe, this preserves the lamellose character of the model liquid flow from the reservoir to plastic hose.

Crater/vent. The natural analogue of this part of the equipment is the crater of a volcano or volcanic bocca. The upper part of the plastic hose enters a transparent aquarium of rectangular cross section made of acrylic plastic. The aquarium is hermetically sealed, so that no liquid can be spilled beyond CAMBE, and is equipped with a discharge device.

The part of the experimental system described above enabled us to monitor processes that occur when liquid passes from the feeding system into an open space.

Registering system. This system includes a unit for dynamic video monitoring, an electronic device for measuring the height, speedometer, video recording unit, acoustic recording unit, synchronizing device, and shut-off system (Fig. 3a).

The unit for dynamic video monitoring is designed for the on-line monitoring and registering of processes in the transparent vertical hose during the flow of the model liquid through it. A camcorder mounted on a 
(a)

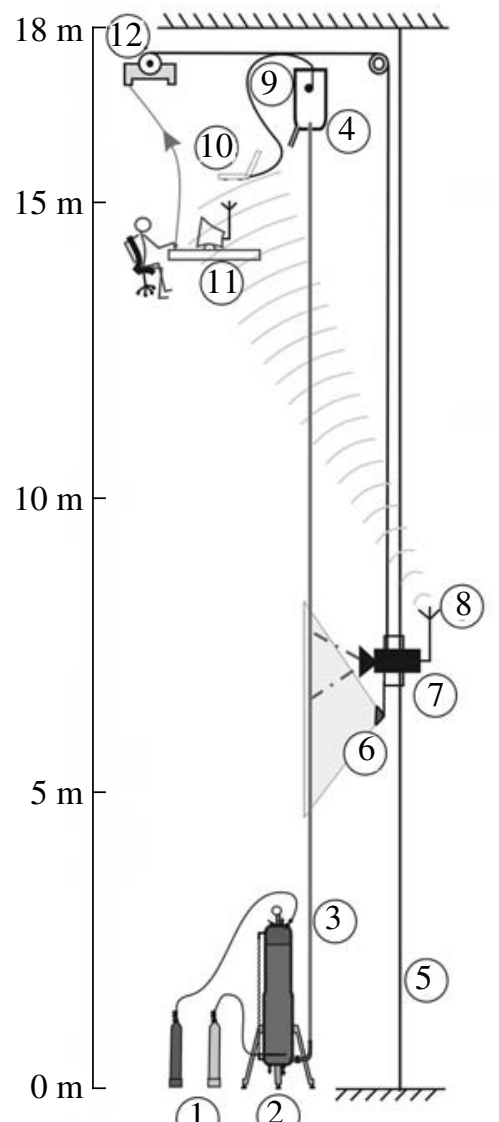

(b)

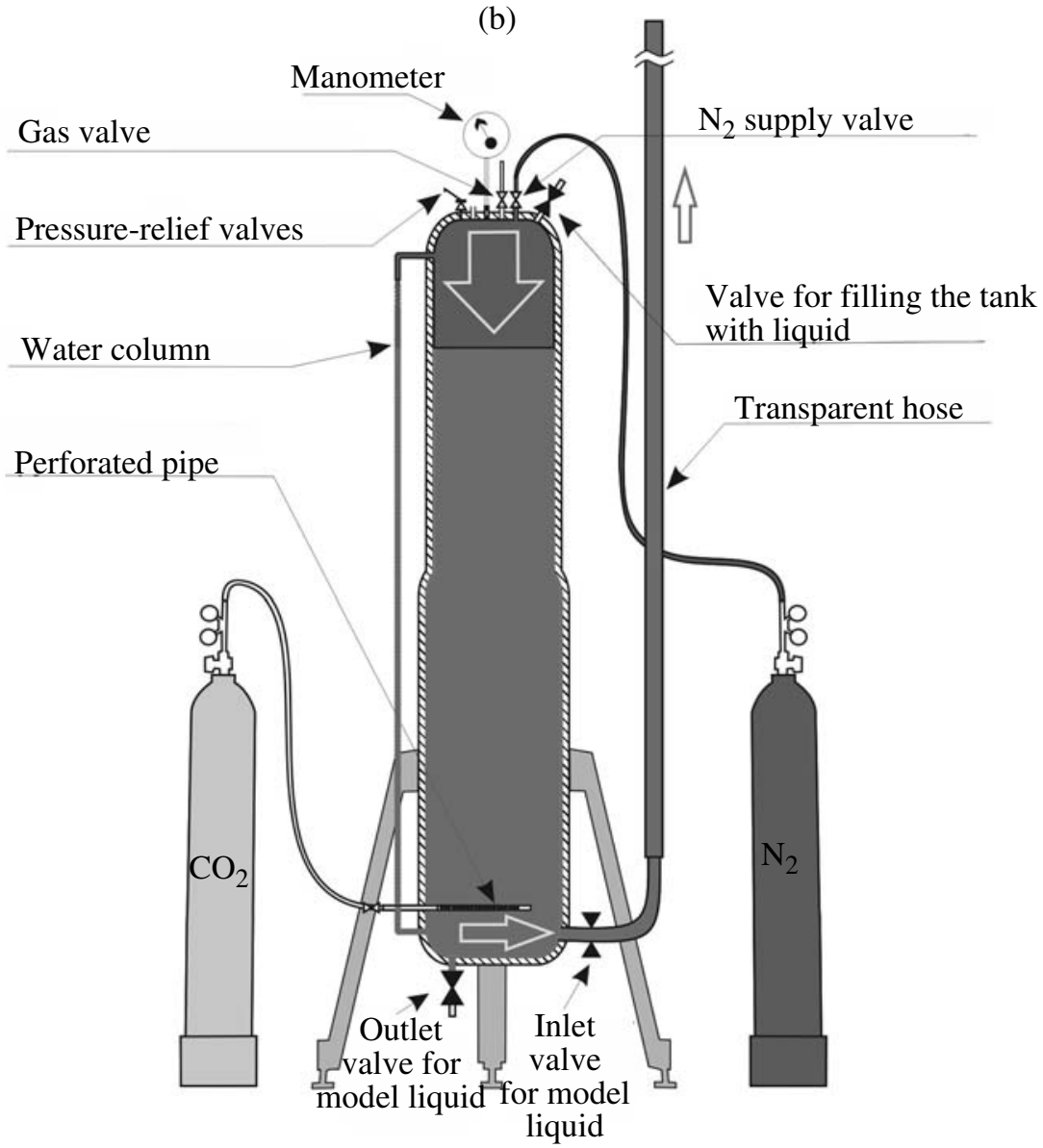

Fig. 3. CAMBE experimental equipment for modeling basaltic eruptions.

(a) Design of (1-4) the modeling and (5-14) units of CAMBE: (1) high-pressure gas tanks with $\mathrm{CO}_{2}$ and $\mathrm{N}_{2}$, (2) hermetically sealed tank for preparing modeling liquid, (3) transparent hose, (4) aquarium for receiving liquid, (5) cable for directing the movement of the dynamic video monitoring car, (6) source of light, (7) camcorder, (8) transmitting set and telemetry antenna, (9) microphone, (10) computer, (11) radio signal receiver and monitor, (12) electric motor. The operator is shown in the upper part of the figure.

(b) Unit for preparing gas-rich model liquid and its pumping to the transparent hose.

ropeway car with an electric motor can move along the hose. A powerful light source mounted on the same car makes it possible to distinguish even small heterogeneities in the flowing liquid. The imagery provided by the camera is transferred to a monitor via a telemetry channel and enables on-line monitoring. The operator at the monitor can use controls to promptly vary the velocity of the car within the range of $2-10 \mathrm{~cm} / \mathrm{s}$.

Height measuring device and speedometer. The height and velocity of the moving car are simultaneously measured by an electronic unit designed and manufactured for this purpose. This unit makes it possible to determine the vertical position of the car accurate to $10 \mathrm{~mm}$ using a height measuring device and to measure changes in its velocity (within the range of 2$10 \mathrm{~cm} / \mathrm{s}$ ) using a speedometer.

Video recording. The experiment is recorded by a video camera, which is mounted on a mobile car and records transformations in the model liquid ascending along the transparent hose. For the convenient observation of the processes, the latter are carried on at an optimal image capture angle that makes it possible to record a video sequence of moving bubbles within a $30-$ $\mathrm{cm}$ vertical interval.

The acoustic system makes it possible to register a sound signal generated during the destruction of bubbles reaching the top end of the hose. For this purpose, a moisture-proof microphone is mounted above the top end of the hose. Digital signals from the microphone are transmitted to a computer and recorded. This is an analogue of a geophysical station recording seismic transients in the vicinity of the vent of an erupting volcano.

The synchronizing unit is utilized to synchronize the video and acoustic signals accurate to a few milliseconds. 
The emergency shut-off system is devised to urgently stop the car carrying the video camera if it exits the working zone.

The modeling system of CAMBE can operate in two modes: in a gas-saturated conduit (model liquid enters the pipe together with dissolved gas) and bubbling conduit (when gas is introduced into the conduit with stationary liquid through a nozzle of small diameter and forms bubbles). It the latter variant, the modeling system is devoid of its "chamber zone", the bubble nucleation stage is absent, but the behavior of the gas phase can be observed in the originally stationary liquid. Most of our studies were conducted with a gas-saturated liquid. The number of experiments in the bubbling conduit was small, and these experiments were carried out to compare their results with those of experiments in the gas-saturated conduit. It is pertinent to stress that all experiments with CAMBE were carried out in open systems.

\section{EXPERIMENTAL}

\section{Experiments in a Gas-Saturated Conduit}

The preparation of the model liquid involves the saturation of $350 \mathrm{l}$ of water by gaseous $\mathrm{CO}_{2}$. The conditions of this process are controlled by a manometer. Our preparatory experiments allowed us to select an optimal pressure for distribute: 1.6 at. This pressure allows model liquid to start releasing the gas in the form of a free gas phase in the lower part of the gas-saturated column and eventually ensures the modeling of all gashydrodynamic regimes.

Preparatorily to the experiments, a transparent hose was filled with water not saturated with gas to stabilize the conditions at the starting moment of time. Simultaneously the inlet valve for nitrogen and the ball inlet valve for the model liquid were opened. Nitrogen exerted an excess pressure in the reservoir, and the ascending model liquid forces out gas-unsaturated water from the hose. After the system is stabilized at a low nitrogen flux rate, the experiments were started, and processes in question could be monitored in the transparent hose. The flow rate of the gas-saturated liquid inflowing into the conduit in the course of each experiment was maintained at a constant level.

It was established during our experiments that the following four gas-hydrodynamic regimes developed in various parts of the conduit during the flow of the gassaturated liquid through this conduit: liquid, bubbly, cluster, and slug (Fig. 4). These regimes are stable and can persist for any period of time at an unvarying inflow rate of the model liquid. Below we present a description of the experiment that we consider basic, because all characteristics of the distinguished regimes are manifested in it at a liquid flow velocity of $3-5 \mathrm{~cm} / \mathrm{s}$. For convenience, the processes occurring during the ascent of the model liquid will be described in the initial $30 \mathrm{~cm}$ of each interval and then tentatively approximated to the whole zone 1-m high.

Liquid regime. This regime occurs within 0-4-m interval (from the bottom) of the vertical conduit. The model liquid with dissolved $\mathrm{CO}_{2}$ gas ascends along the hose. This is a regime of laminar homogeneous flow, without any heterogeneities in the flow (Fig. 4). No bubbles are formed during the liquid regime, and all gas is dissolved in the liquid. The model liquid is homogeneous, and thus no movements occur in the ascending gas-saturated column within this interval. The pressure decrease results in a transformation of the gas-saturated liquid and brings about conditions favorable for the release of a gas phase are thus created.

Bubbly regime. This regimes occurs in the vertical column within the interval of 5-12 m (Fig. 4). The onset of this regime is marked by the appearance of the first bubble. Starting at that time, the column is characterized by a two-phase flow regime of the model liquid. The transition to the bubbly regime is almost indiscernible. The first bubbles nucleating in the liquid are very small $(<1 \mathrm{~mm})$ and are thus hard to distinguish. The nucleation process is initially very slow, and only single bubbles can be detected in the lower part of the column $(5-7 \mathrm{~m})$. The nucleation rate gradually increases to 60 bubbles at a height of $11 \mathrm{~m}$. The newly formed bubbles are $<1 \mathrm{~mm}$ throughout the whole column. Farther up the column, in the transition zone to the next regime, bubbles formed in the lower part of the interval of the bubbly regime grow to 7-9 $\mathrm{mm}$ across. When moving upward, bubbles have different velocities, can accelerate or decelerate, and increase in size. As the liquid ascends, more and more bubbles are formed in it (Fig. 4), so that the upper parts of the interval are characterized by the bubbly regime with a number of populations (generations) of bubbles, more specifically, with a gradual transition from smaller (newly formed) to larger (formed at lower levels of the column) bubbles.

The distribution of bubbles along the column is as follows: they are relatively evenly distributed in the lower part of the column and, farther upward, form clusters (swarms) alternating with intervals containing lower amounts of bubbles. The initial velocity of bubbles is $25-30 \mathrm{~cm} / \mathrm{s}$ (relative to the walls of the conduit) and increases to $40 \mathrm{~cm} / \mathrm{s}$ in the course of their ascent.

Cluster regime. This regime occurs in the experimental column within the height interval of 13-14 m (Fig. 4). An increase in the number and size of the bubbles results in a structural transformation of the gas-liquid flow: the distance between individual clusters notably increases, and the clusters become more closely packed. This gives rise to clearly pronounced swarms of bubbles, which are transformed into individualized bubble clusters commonly comprising from 20-35 to 50 closely spaced bubbles (Fig. 4). The clusters are separated from one another by liquid practically devoid of the free gas phase. The length of the clusters amounts to 2-3 diameters of the pipe (30-35 $\mathrm{mm})$, and the clus- 
(a)

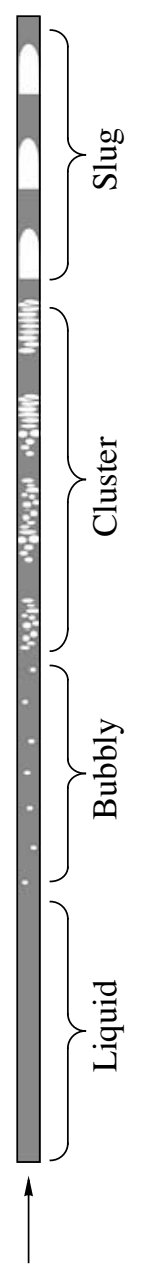

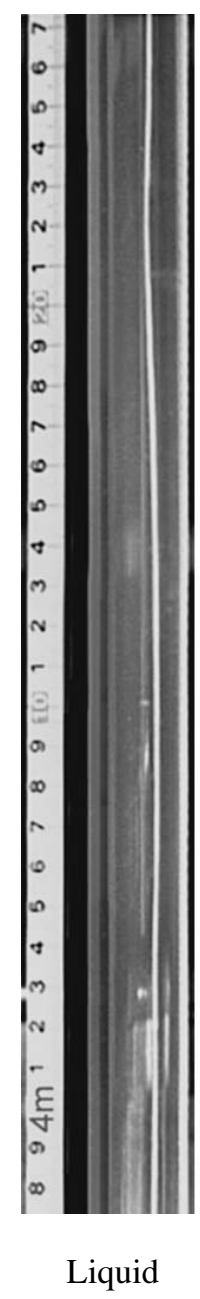

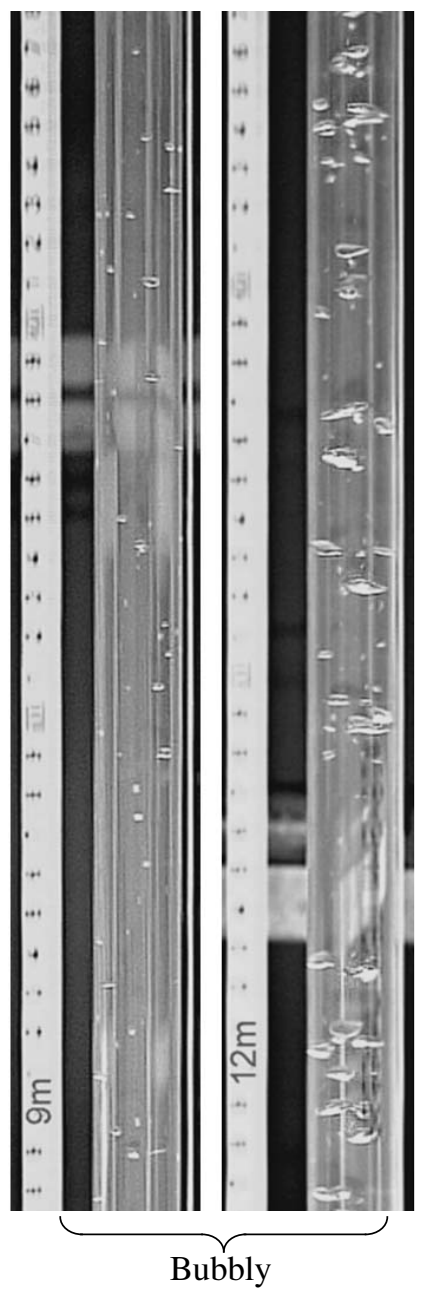

(b)

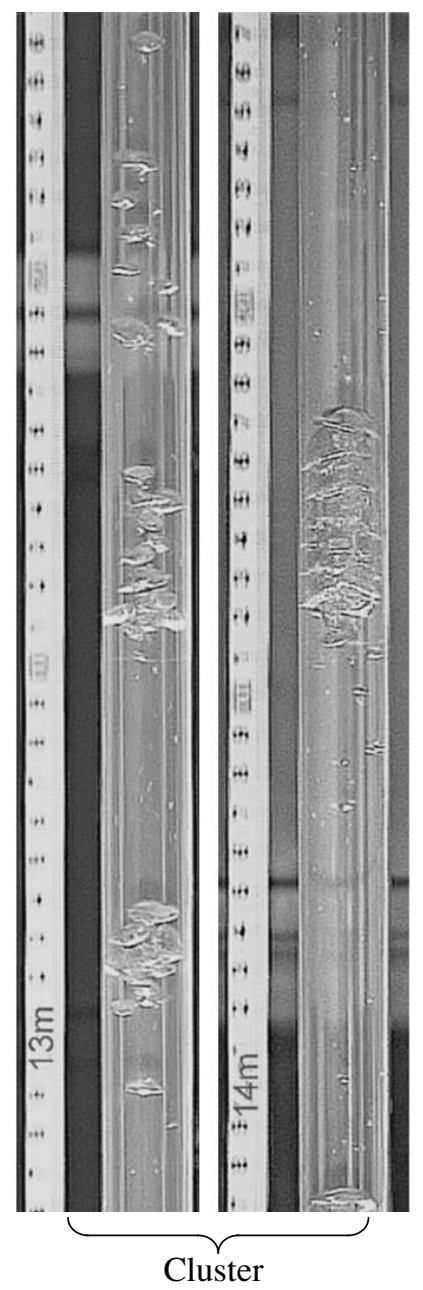

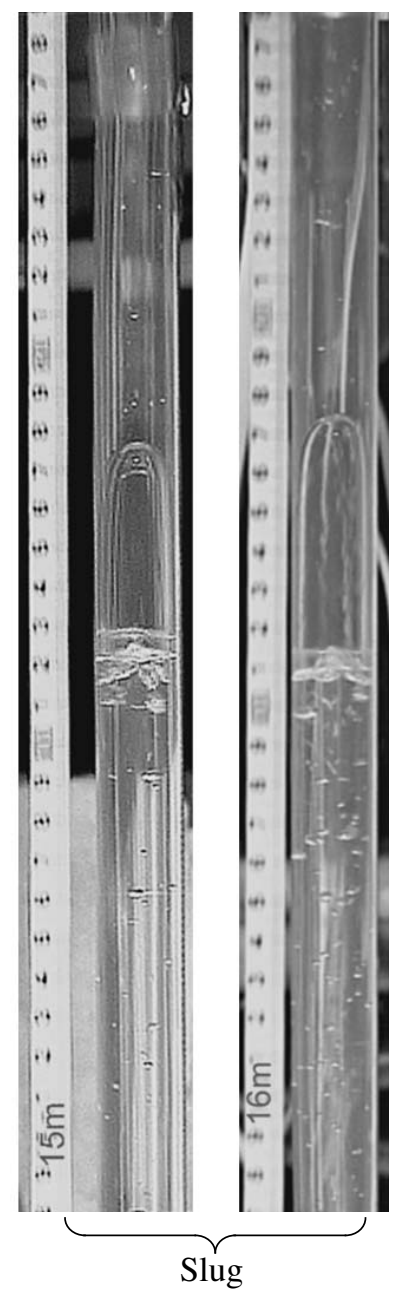

Fig. 4. Fragments of gas-hydrodynamic regimes developing during the ascent of gas-rich liquid up the transparent hose. (a) Schematic arrangement of the gas-hydrodynamic regimes in the column.

(b) Still-frame images of the flow regimes of gas-rich model liquid through the vertical conduit. The tape measure with height marks is shown in the left-hand part of each still-frame. All still-frames images of the successive evolution of the model liquid were taken in the course of a single pass of the camcorder along the column with a velocity equal to the ascent velocity of the gas phase.

ters are separated by a space of 7-9 diameters of the pipe from one another (are spaced 120-160 mm apart). The experimental column contains approximately ten individual clusters at any moment of time, with these clusters equally separated from one another when ascending. The velocity of the clusters relative to the walls of the conduit is $\sim 35 \mathrm{~cm} / \mathrm{s}$. In the mature cluster regime, bubbles have convex-concave shapes, are enclosed in one another, and form a specific dynamic close packing of bubbles.

The following two types of bubble clusters are successively formed (Fig. 4). In the lower part of the cluster regime $(13 \mathrm{~m})$, "open" clusters are formed, which are modified into "blocked" clusters when ascending. The open clusters consist of bubbles similar in diameter, and the bubbles of these clusters can swap places and outrun one another when the cluster ascends. The blocked clusters are made up of bubbles that follow a single larger bubble. The morphology of the blocked clusters is such that they cling to the inner walls of the pipe and practically clog its whole diameter.

Slug regime. The interval in which this regime occurs in the vertical column is $15-16.6 \mathrm{~m}$ (Fig. 4). The further structural transformation of the two-phase system is caused by the rupture of walls between neighboring bubbles in clusters. One large bubble develops in the upper part of the cluster (the coalescence process proceeds from bottom to top), and the cluster becomes eventually transformed into a clearly individualized slug that is 3-4 pipe diameters long (Fig. 4). Each of the slugs covers practically the whole cross section of the pipe and leaves only a thin (almost indiscernible) conduit of circular cross section for the backflow of the liquid. With respect to the ambient liquid, slugs are large 
gas-filled voids. Their lengths increase with the ascent of the liquid, and the number of smaller bubbles following them also increases. However, the overall morphological transformations of the slugs are not very significant.

The column simultaneously contains approximately ten equally spaced moving slugs, which form a peculiar structure resembling beads. Upon reaching the surface, the slug bursts, and each surge of the model liquid corresponds to the arrival of another slug to the surface. This is well illustrated by the acoustic record at CAMBE (Fig. 1c). The background volume of the signal corresponds to the outpouring of a certain volume of the model liquid moving between slugs. The velocity of the slugs is slightly higher than that of the clusters: approximately $40 \mathrm{~cm} / \mathrm{s}$. The slug regime is the most stable among those observed in our experiments: the shapes of the gas slugs, their volume, and the spacing in between practically do not vary until the slugs reach the top end of the pipe.

The description presented above corresponds to the situation when the gas-saturation pressure in the reservoir is $1.6 \mathrm{~atm}$, and the velocity of the model liquid coming into the vertical column is $3-5 \mathrm{~cm} / \mathrm{s}$. A set of experiments was conducted under this gas saturation pressure and a broad range of the model liquid velocity (from 1 to $10 \mathrm{~cm} / \mathrm{s}$ ). The general structure of the gashydrodynamic flow and the transition from one to another regime remained similar to those in the main experiment (see above).

Under lower gas-saturation pressures, the gas phase was liberated in the experimental column later (at a higher level), and the gas-saturated flow did not evolve through all of the regimes described in the main experiment. Under low pressures of 0.3-0.4 atm, the gas phase has no time to leave the model liquid, and hence, the liquid regime will occur at the surface. An increase in the saturation pressure in the reservoir results in that more and more mature and evolved regimes of the gassaturated flow occur at the surface in each next experiment. Thus, any of the four regimes described in the main experiment can reach the surface (depending on the gas saturation conditions), i.e., the top end of the hose, and this allowed us to model various types of volcanic eruptions.

\section{Studies in the Bubble Column}

Our CAMBE experiments have shown that the processes of bubble structuring taking place in a column with a stationary liquid are the same as in the gas-saturated column described above. The stationary ascending bubble flux evolves into gas clusters, which are transferred into slugs during the further ascent of the liquid. The bubble column thus allowed us to model three regimes: bubbly, cluster, and slug.

\section{DISCUSSION}

I. The results of our experiments on CAMBE notably bridge gaps in current gas-hydrodynamic, concepts that underlie volcanologic interpretations of the movement dynamics of basaltic melts. Our experimental results show certain characteristics that have never before been taken into account during the hydrodynamic modeling of volcanic eruptions.

(1) Our model was the first to take into consideration the geometric parameters of volcanic conduits of basaltic volcanoes. The lengths of these feeders are a few orders of magnitude greater than their diameters, and hence, the ratio of the inner diameter of the conduit to its height in CAMBE is close to $1: 1000$.

(2) Our physical model was the first to imitate the ascent conditions of a gas-saturated liquid along a conduit and to enable the monitoring of gas bubble nucleation, their subsequent growth (increase in their size), and the development of bubble clusters and slugs.

(3) Our experiments allowed for the forced steady ascent of the model liquid along the column and enabled us to get rid of various structural barriers and fluctuations in the velocity of the gas-saturated liquid.

II. The experiments were carried out with a homogeneous model liquid that evolved into a two-phase system (liquid + gas) during its ascent along the vertical conduit. This process is associated with the successive development of the following four gas-hydrodynamic regimes: liquid, bubbly, cluster, and slug, which systematically grade into one another (Fig. 3).

The gas-hydrodynamic regimes start to develop when the first gas bubble nucleates in the liquid and continue until the onset of the mature slug regime. These regimes define the following clearly pronounced evolutionary succession: dissolved gas gas bubble cluster of bubbles gas slug, which manifests liquid polymorphism. Polymorphism is currently understood as the ability of simple or complex compounds to form two or more polymorphic modifications that have the same chemical composition but different physicochemical characteristics. Phase transitions and various polymorphs of a chemical composition are referred to as polymorphic. Our experiments show that a compound of unchanging composition (water and carbon dioxide dissolved in it) can evolve in principally distinct modes of occurrence, i.e., demonstrate obvious gas-hydrodynamic polymorphism. The regimes distinguished in our experiments (liquid, bubbly, cluster, and slug) should then be regarded as polymorphic modifications, the structure of the moving liquid as a whole can be referred to as a polymorphic current, and the movement process itself can be named polymorphic flow.

III. Our experiments led us to discover a previously unknown link between the bubbly and slug regimes; we propose to name this regime cluster (Fig. 4). This is a newly recognized stable gas-hydrodynamic regime, which has not been described in any earlier reviews (Wallis, 1969; Kutateladze and Nakoryakov, 1984; 
Ertel, 2007) or publications devoted to the operation of large oil wells (Abishev et al., 1981; Sakharov and Mokhov, 2004).

The principal characteristics of the cluster regime are as follows: (1) its basic unit is a cluster of bubbles, which is a volume of liquid with a high concentration of gas bubbles restricted by bubble-free liquid from above and below; (2) a set of regularly spaced bubble clusters following one another defines the cluster regime; (3) the cluster regime always develops between the bubbly and slug regimes; (4) the cluster structures are characterized by a stable character persistently present at certain intervals of the column; (5) the clusters can be classified into two morphological types: open and blocked; (6) the ascent velocities of clusters are lower than those of large bubbles and slugs; (7) the lifetime of the cluster regime is comparable with those of the bubbly and slug regimes; (8) the cluster regime can develop in a broad range of hydrodynamic conditions: in the bubble column (at a zero velocity of the liquid and without dissolved gas) and in a gas-saturated column (with liquid velocity in the range of $1-10 \mathrm{~cm} / \mathrm{s}$ ); and (9) the development of clusters is controlled by the interaction of large gas structures with the walls of the conduit and the processes of clogging and deceleration.

The author believes that the cluster regime is not only typical of volcanic phenomena but can be regarded as an individual regime of gas-liquid mixtures: for example, in natural hydrothermal systems and mud volcanoes, in the modeling the operation of hydrothermal and oil wells, and in the chemical industry.

IV. Below we present a detailed description of the mechanism forming the cluster regime (Fig. 4). The precursors (nuclei) of would-be clusters are readily discernible in the upper part of the column, where the bubbly regime occurs. This interval is characterized by an uneven distribution of bubbles, which definitely compose aggregates of a number of individual bubbles. These aggregates become pronounced more clearly early in the cluster regime. At a certain moment of time, a bubble or aggregate of smaller bubbles starts to interact with the walls of the conduit. The further increase in the size of the bubbles results in a notable decrease in the cross section of the backflow conduit, which is free space (of circular cross section) between the gas structure and the walls of the conduit. The aggregate of bubbles thus clogs the liquid flow and hence decelerates the ascent of the bubble or bubble aggregate. The velocity of the bubbles decreases, and they act as a clog for other bubbles ascending from below. The latter bubbles accumulate below the clog, spacing between them diminishes, and eventually a great number of bubbles produce a new gas structure: a cluster of bubbles. Bubbles occurring $\mathrm{n}$ the conduit above the newly formed cluster continue to ascend with an unchanged velocity, and thus a volume of liquid devoid of bubbles is formed above the cluster. Another bubble-free volume of liquid is generated below the cluster under the effect of another cluster developing at a lower level.

$\mathrm{V}$. The clusters start to evolve into slugs in the upper part of the mature cluster regime. This process occurs in blocked clusters, in which bubbles cling to one another and the inner walls of the conduit. This close dynamic packing inevitably leads to the coalescence of the bubbles, so that they eventually form a larger gas bubble in the upper portion of the cluster. The bubbles begin to merge (i.e., form a slug), and this process proceeds from the lower part of the cluster to its top, so that the whole gas cluster is eventually transformed into a classic gas slug.

The slug regime was the most stable in our experiments, could survive for infinitely long time, and did not grade into any other regime, although the parameters of this regime itself evolved in the course of the experiments. For instance, a pressure drop ensures gas diffusion from the model liquid to slugs, and this results in an increase of their longitudinal sizes and accelerates their ascent. This, in turn, leads to the development of a lower pressure zone below the bottom of a slug, as follows from the occurrence of a concave meniscus in the slug bottom. The turbulence of the model liquid beneath the slug becomes more significant, and a new nucleation stage begins: the amount of small bubbles drastically increases at the rear part of the slug. The slug regime persistently comprises two regimes: the initial slug regime or the slug regime proper, when practically no gas bubbles occur at the rear parts of the ages slugs, and the mature slug regime, when slugs are followed by trains of smaller bubbles.

VI. It is now pertinent to consider in more detail the velocity of two-phase flows whose evolution leads to the development of clusters and slugs. Our experiments indicate that the structuring of the gas phase, up to the development of gas clusters and slugs, can occur within broad ranges of velocities and under various gas-hydrodynamic conditions. This obviously follows from the results of two sets of our CAMBE experiments: with a gas-saturated column (liquid velocity from 1 to $10 \mathrm{~cm} / \mathrm{s}$ ) and a bubble column (gas bubbles through stationary liquid). In all situations the same sequence of gas structuring took place: gas bubble gas cluster gas slug. Hence, the gas structures developing in the columns experience the same morphological evolution. This testifies that the recognized gas structures are inherent to vertical gas systems and can be generated within a broad enough range of velocities. It is thus reasonable to suggest that the gas phase of natural basaltic feeding systems undergoes the same successive structural evolution as in our experiments.

VII. Manifestations of each of the gas-hydrodynamic regimes is convenient to consider at the upper part of the gas pipe, because this part of CAMBE can model all processes in the vent zone of basaltic volcanoes. Depending on the content of dissolved gas in the model liquid, any of the regimes described herein can 
Classification of the types of eruptive activity at basaltic volcanoes depending on the gas-hydrodynamic regimes in their vents

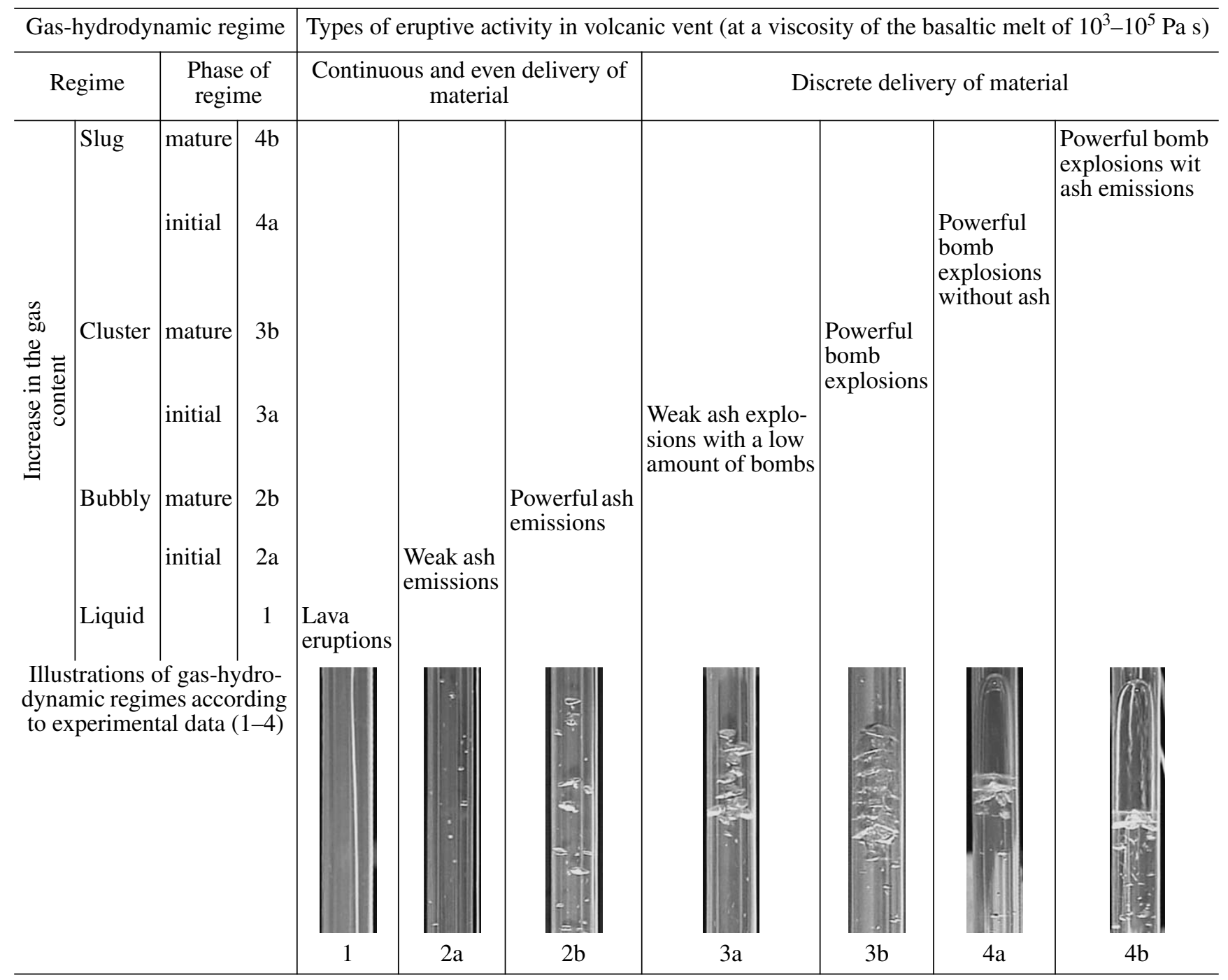

brought to the surface. Below we compare the surface effects of each regime with the dynamic parameters of basaltic eruptions (table, Fig. 4).

Liquid regime. No gas is contained in the system as a free phase, and the model liquid is constantly outpoured at an equal flow rate from the top end of the pipe. The liquid regime corresponds to the quiet (without explosions) even lava outpouring at volcanoes.

The bubbly regime is defined by an steady flux of bubbles that burst at the surface of the liquid. Depending on the content of bubbles, their sizes, and magma viscosity, manifestations of this regime in nature can be very diverse in character and scale. Liquid magmas can "boil" at the surface of lava lakes and weakly gush in volcanic vents, while more viscous magmas give rise to more steady continuous ash emissions due to the rupture of walls between gas bubbles reaching the surface. This regime is characterized by an unvarying flux of gas bubbles ascending to the surface for a long time.
The cluster regime is characterized outbursts of the model liquid at the exit of the conduit due to the development of bubble clusters alternating with the quiet outpouring of the model liquid. The cluster regime in liquid magmas in the crater zones of volcanoes is manifested as the quasiperiodical development of growing gas bubbles or brief discrete lava fountains (outbursts). More viscous melts generate ash ejections without only scarce (if any) bombs (Fig. 5a). Volcanic bombs are formed due to a decrease in the thickness and eventual breakup of the magma layer above a cluster and the destruction of large bubble walls within it, while finer tephra fractions are produced by the destruction of the thinner walls of smaller bubbles in the cluster. These manifestations become more active and effective during the mature cluster regime.

The slug regime at the exit from the conduit is characterized by significant outbursts of the model liquid caused by the rupture of the liquid layer overlying gas slugs that reached the surface. Outbursts alternate with 

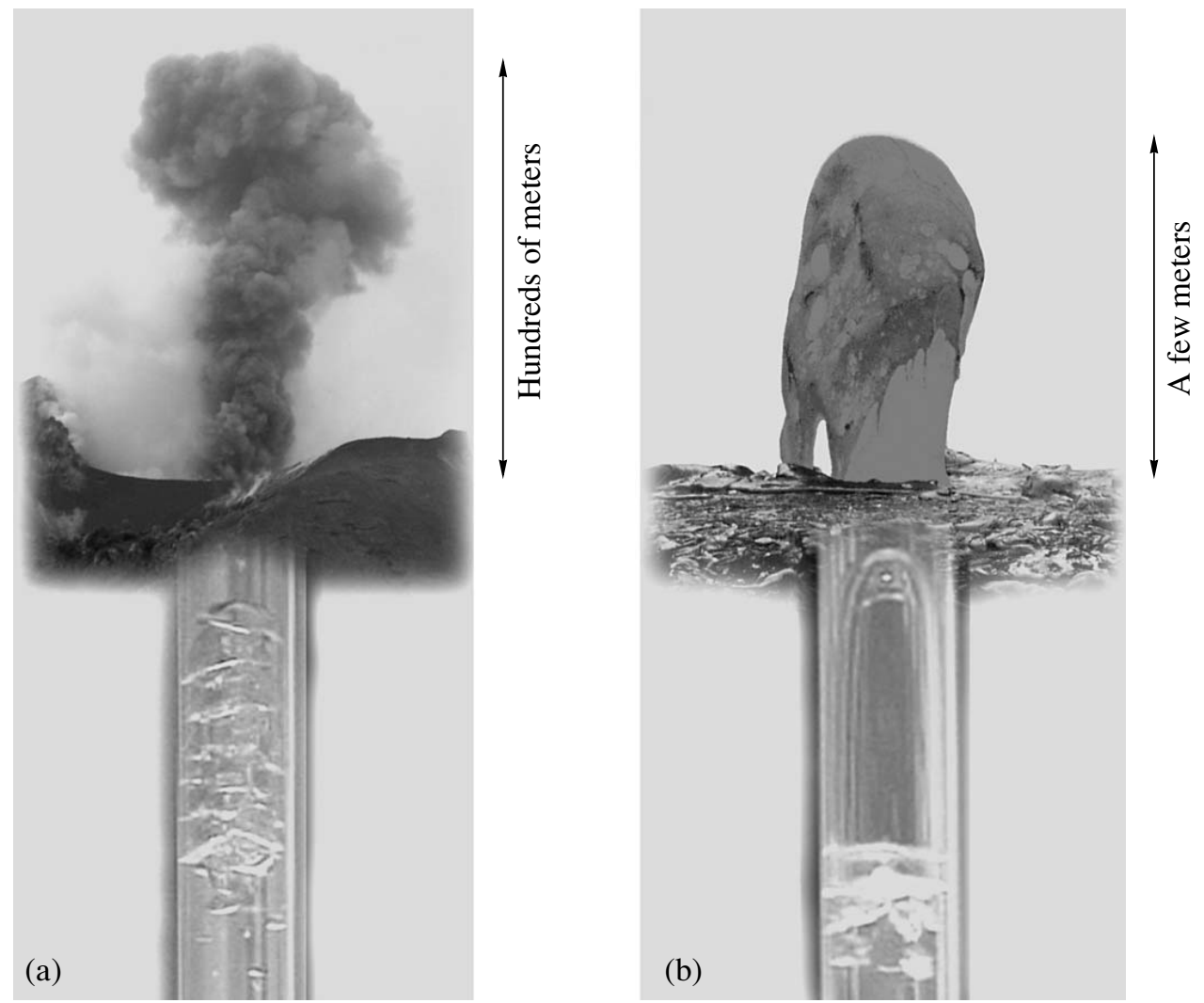

Fig. 5. Model for explosive ejections/explosions when the cluster and slug regimes reach the surface.

The lower parts of the figure show the gas structures detected in the course of our CAMBE experiments, and the upper parts display naturally occurring volcanic events: (a) the 2004 ash ejection at Stromboli volcano (photo: A.Yu. Ozerov) and (b) a lava bubble (Bourseller and Durieux, 2001).

the quiet outpouring of the liquid and its ascent along the column (Fig. 4). The slug regime is subdivided into two stages: (1) the earlier slug stage proper, when the ages slug is practically not followed by any small bubbles, and the alter slug-train stage, when the slug is accompanied by a stable train of small bubbles. The slug regime proper occurring during the volcanic eruptions of more liquid lavas corresponds to the pop-ups of lava bubbles (Fig. 5b) or drastic lava outbursts. In more viscous magmatic melts, the "roof" of the slug is rapidly ruptured, and this results in powerful discrete ejections of bombs. During the slug-train stage, bomb ejections are associated with the emission of volcanic ash, which is generated by numerous small bubbles that follow a slug.

Manifestations of the cluster and slug regimes in the crater zone show many similarities (lava bubbles, outbursts, ejections of bombs, volcanic ash) and certain differences, which are caused by the inner structure of the gas structures. The cluster is a cellular foamy structure, whose bubbles are separated by dividing walls; the latter form a framework that fills the whole cluster. As the cluster is exposed at the surface, the walls of its bubbles are successively ruptured. Depending on the size of bubbles in the cluster, ash or bomb-ash ejecta are formed at the surface. In contrast to the cluster, the gas slug is a single gas-filled void and causes a single burst of the upper magma layer at the surface; this situation corresponds to ejecta dominated by volcanic bombs.

The development of the cluster or slug regimes significantly redistributes potential energy in the magmatic column, and an increase in the viscosity of the melt results (at other factors being equal) in a significant increase in the gas impulses, up to explosions.

VIII. The main criterion used in physics for defining any explosion is the shock wave generated during the ejection and expansion of material (Polytechnic Glossary, 1976; Kobylkin et al., 2004). Seismic waves generated during eruptions of various volcanoes were described in (Adushkin et al., 1984) and were registered during the 1983 and 1987 eruptions of Klyuchevskoi and 1975-1976 eruption of Tolbachinskii volcanoes (Firstov et al., 1978; Storcheus et al., 1983; Firstov and Storcheus, 1987; Firstov, 2003). Using acoustic registration, these researchers have recognized five types of seismic waves generated by volcanic ejects. They considered impulses occurring during volcanic eruptions from the viewpoint of physics, i.e., as lowdensity shock waves. The analysis of seismic wave parameters at Klyuchevskoi and Tolbachinskii volca- 
noes made it possible to quantify the ejection energy, which was evaluated at approximately ten tons of TNT equivalent for weak eruptions and one hundred tons of TNT equivalent for powerful eruptions. In the situations considered above (Klyuchevskoi and Tolbachinskii volcanoes), seismic waves were registered at a melt viscosity of $10^{3}-10^{5} \mathrm{~Pa}$. At exactly those values of melt viscosity, walls in a cluster or a magmatic melt layer beneath a slug are still plastic during melt ascent but behave as a rigid solid during the instantaneous release of the potential energy of the compressed gas when the cluster or slug reaches the surface, and this ensures the generation of shock waves.

IX. We compared the acoustic record of the slug regime at the upper end of the CAMBE experimental column with the seismic record of the explosive activity at the Klyuchevskoi summit crater. Figures $1 \mathrm{~b}$ and $1 \mathrm{c}$ clearly show that the experimental and natural signals display several similarities. In both cases, they are generated by discrete quasiperiodic processes of variable amplitude. This led us to suggest that the gas-hydrodynamic processes observed in CAMBE experiments and taking place in natural magma feeders are of similar nature.

It should be mentioned that events at Klyuchevskoi volcano and in CAMBE were registered by different techniques: seismic and acoustic, respectively. Trains of basic magma explosions recorded by these two techniques usually differ in the duration of the train: the wavetrains of the acoustic signal are much shorter that the seismic one. Thereby the background signal is usually not high. The higher acoustic background at CAMBE (Fig. 1c) is explained by the proximity of the registering microphone to the sound source: the end of the pipe from which the liquid is continuously outpoured, and this accounts for the high background level. If the registered events could be registered by similar techniques and the background amplitude for the flowing liquid could be diminished, then the compared volcanic and model records were undoubtedly more similar.

$X$. With regard for data on the energy of powerful discrete explosions, magma viscosity, and the results of our model experiments, the following scenarios can be proposed for the explosion mechanisms of basaltic magmas (table): (1) weak explosions with little (if any) volcanic bombs, which corresponds to the initial phase of the cluster regime; (2) powerful ash-bomb explosions, which corresponds to the cluster regime; (3) bomb explosions grading into ash explosions, which corresponds to the slug regime proper; and (4) bomb grading to ash explosions, which corresponds to the mature slug-train regime with trains of small bubbles. It follows that an increase in the amount of the gas phase in the flow results first in an increase in the amount of ash (bubbly and cluster regimes), then in its decrease (slug regime), and, finally, in another increase (slug-train regime). The aforementioned information testifies that different types of Strombolian activity at basaltic volcanoes are generated by different types of their gas-hydrodynamic regimes that develop in the gas-saturated melts ascending through long vertical conduits.

XI. In describing the mechanisms responsible for the development of the cluster and slug regimes are and with regard for natural observations at basaltic volcanoes, it is possible to propose a new definition for a basic concept of Volcanology: an explosion of basaltic magma.

An explosion of basaltic magma is a virtually instantaneous release of energy that results in a discrete ejection of a significant volume of volcanic gas and disintegrated low-viscosity magmatic melt $\left(10^{3}-10^{5} \mathrm{~Pa} \mathrm{~s}\right)$ at the surface. Large individualized gas segregations are generated by a complex of polymorphic gas-hydrodynamic transformations in the vertical magma feeder. Because of a decrease in the hydrostatic pressure, a gasrich melt ascending along a magmatic feeder passes through the following four evolutionary regimes: liquid, bubbly, cluster, and slug. Each of these regimes is pronounced during eruptions of basaltic volcanoes, and each of these regimes always occurs in series. Such explosions are known at Klyuchevskoi, Tolbachinskii, Stromboli, Etna, Erebus, and other volcanoes. An average basaltic magma explosion ejects approximately 30-100 tons of magmatic material at the surface.

When our data are analyzed, it should be mentioned that it is still hardly possible to apply physical equations and dimensionless parameters with the transition from CAMBE experiments to the natural feeding system of a basaltic volcano, contrary to what was proposed in (Landau and Lifshits, 1944; Sedov, 1987). One of the reasons for this is that the cluster regime, which was first described in this publication, still has never been formalistically described.

\section{MAJOR CONCLUSIONS}

(1) In order to examine the character of magmatic melt flow through the feeding system of a volcano, an experimental setup (CAMBE) was designed and manufactured. This experimental equipment is able to model basaltic eruptions and serves to study processes taking place during the generation, ascent, and outpouring at the surface of a two-phase gas-liquid flow flowing through a vertical conduit.

(2) The analysis of the diverse flow regimes of a single model liquid led us to recognize the following four regimes: liquid, bubbly, cluster, and slug, which are generated in the course of the systematic evolution of the gas-rich flow and are characterized by certain distinctive morphological features. This testifies to structural gas-hydrodynamic polymorphism of a liquid flow, and the aforementioned regimes are, respectively, polymorphic modifications of the gas-rich liquid flow. 
(3) Our CAMBE experiments led us to recognize and describe a previously unknown flow regime of twophase mixtures in a vertical conduit: this is the cluster regime, which is characterized by systematically alternating of compact segregations (clusters) of gas bubbles and liquid free of such bubbles in between. The clusters are generated due to the interaction of large gas structures with the walls of the conduit. This regimes brings about the effects of self-clogging and hampering of the flow and produces a slowly ascending dynamic gas clog: cluster.

(4) Our studies allowed us to propose a new model for the gas-hydrodynamic evolution of moving magmatic melt in the feeder of a basalt volcano. The surface manifestations of various flow regimes of two-phase mixtures are responsible for the diversity of explosion phenomena in volcanic craters. Depending of the type of the regime, the volcanic vent can be characterized by the steady or discrete supply of magma material and, respectively, the continuous lava outpouring and ash emission in the former situation and ash, bomb, and ash-bomb explosions in the latter.

(5) The analysis of the reasons for the major explosion types of basaltic magmas in volcanic vents allowed us to explain them from the standpoint of the gashydrodynamic regimes: (i) weak ash eruptions with a low amount of bombs early in the cluster regime; (ii) powerful ash-bomb explosions during the mature cluster regime; (iii) bomb explosions during the initial slug regime; and (iv) bomb explosions grading into ash explosions, corresponding to mature slugs followed by trains of small gas bubbles.

(6) Studies of the character of explosions at basaltic volcanoes with regard for our experimental data permitted us to define the mechanism that prepares basaltic magma explosions from a new standpoint. This preparation is regarded as the gas-hydrodynamic transformation of magmatic melt ascending along the vertical feeding conduit of a volcano.

\section{ACKNOWLEDGMENTS}

The author thanks V.A. Droznin for help during the long-term research. Much help and assistance for this study was provided by the directorship of the Institute of Volcanology and Seismology, Far East Division, Russian Academy of Sciences: Academician of the Russian Academy of Sciences E.I. Gordeev, Academician of the Russian Academy of Sciences S.A. Fedotov, Ya.D. Murav'ev, G.A. Karpov, N.I. Seliverstov, V.A. Kazantsev, I.R. Abubakirov, G.P. Avdeiko, M.A. Alidibirov, G.I. Anosov, Yu.A. Babushkin, A.B. Belousov, V.I. Belousov, O.E. Bograd, K.A. Bychkov, A.V. Butkach, G.F. Vasil'ev, T.D. Vislova, M.G. Gavrilenko, A.A. Gavrilov, V.A. Gavrilov, Yu.V. Demyanchuk, O.I. D'yachkova, R.L. DuninBarkovskii, V.N. Dub-rovskii, V.I. Dyadin, V.V. Ivanov, Jr., S.V. Kas'yanov, V.A. Kirichenko, A.S. Konov,
D.Yu. Kuzmin, Yu. D. Kuzmin, A.V. Lander, V.L. Leonov, S.F. Laktionov, V.S. Lutaya, A.P. Maksimov, V. Martynova, M.A. Mokhov, A.A. Mul'keev, A.V. Mushinskii, A.A. Nuzhdaev, N.A. Ozerova, N.A. Ozerova, Jr., L.G. Osipenko, I.L. Ototyuk, V.K. Panov, S.I. Plotnikov, E.G. Ponomarev, V.G. Pushkarev, A.A. Razina, V.A. Rashidov, A.N. Rogozin, N.V. Romanov, A.P. Sakorenko, I.Yu. Svirid, V.A. Sergeev, A.V. Storcheus, I.F. Timofeeva, G.P. Timoshenko, A.P. Khrenov, V.N. Shapar', V.A. Shirokov, V.P. Shpak, V.S. Shul'ga, O.V. Fidoristov, P.P. Firstov, Yu.V. Frolova, I.V. Chaplygin, O.V. Chaplygin, S.A. Chirkov, O.S. Chubarov, and V.A. Churikov. I appreciate help provided by the administration of the Kamchatka kray: the deputy head of the government V.N Karpenko, A.A. Gavrilov, L.A. Grachev, G.F. Vasil'ev, and S.I. Kravets. The author thanks his foreign colleagues: J. Eichelberger, R. Joyless, F. Kyle, and J. Lies. The author appreciates help provided during the preparation of the manuscript by Acad. V.I. Kovalenko, Acad. V.V. Adushkin, Prof. N.N. Sysoev, Prof. Yu.D. Chashechkin, and Dr. A.A. Gusev. This study was financially supported by the Russian Foundation for Basic Research, project no. 09-05-00841-a.

\section{REFERENCES}

1. S. K. Abishev, R. R. Bulgakov, and V. A. Sakharov, "Experimental Apparatus for Studying the Movement of Gas-Liquid Mixtures in Vertical Pipes for the Ascent of High-Viscosity Oils," Tr. MINKh I GP, issue 156, 98104 (1981).

2. V. V. Adushkin, Yu. A. Gostintsev, and P. P. Firstov, "Nature of Air Waves during Strong Explosive Eruptions," Vulkanol. Seismol., No. 5, 3-11 (1984).

3. A. A. Ariskin, G. S. Barmina, A. Yu. Ozerov, and R. L. Nil'sen, "Genesis of High-Alumina Basalts from Klyuchevskoi Volcano," Petrologiya 3 (5), 42-67 (1995) [Petrology 3, 449-472 (1995)]

4. S. T. Balesta, B. V. Ivanov, V. K. Utnasin, et al., "Structure of the Earth Crust of the Klyuchevskoi Group of Volcanoes, Specifics of Tectonics and Volcanism," in Deep Structure and Modern Activity of the Kyuchevskoi Group Volcanoes (Vladivostok, 1976), pp. 6-15 [in Russian].

5. Ph. Bourseller and J. Durieux, Volcans des et des Hommes (2001).

6. C. R. Carrigan, G. Schubert, and J. C. Eichelberger, "Thermal and Dynamical Regimes of Single- and TwoPhase Magmatic Flow in Dikes," J. Geophys. Res. 97 (B12), 17.377-17.392 (1992).

7. B. Chouet, G. Saccorotti, M. Martini, et al., "Source and Path Effects in the Wave Fields of Tremor and Explosions at Stromboli Volcano, Italy," J. Geophys. Res. 102 (B7), 15129-15150 (1997).

8. S. La. Delfa, G. Patane, R. Clocchiatti, et al., "Activity of Mount Etna Preceding the February 1999 Fissure Eruption: Inferred Mechanism from Seismological and Geochemical Data," J. Volcanol. Geotherm. Res 105, 121-139 (2001). 
9. V. A. Droznin, "Nature of Volcanic Eruptions," in Proceedings of 1st Urban Conference of Young Scientists and Specialists (Dal'nevost. Knish. Izd., PetropavlovskKamchatskii, 1969), pp. 4-6 [in Russian].

10. V. A. Droznin, Physical Model of Volcanic Process (Nauka, Moscow, 1980) [in Russian].

11. G. Ertel', A Prandtle Guidebook on Hydroaerodynamics (IKI, Moscow-Izhevsk, 2007) [in Russian].

12. S. A. Fedotov, "Magmatic Feed Systems and the Mechanism of Klyuchevskoi Volcano Activity," Vulkanol. Seismol., No. 3, 23-45 (1993).

13. S. A. Fedotov, Magmatic Feed Systems and Mechanisms of Volcanic Ejections (Nauka, Moscow, 2006) [in Russian].

14. S. A. Fedotov, N. A. Zharinov, and V. I. Gorel'chik, "Deformation and Earthquakes of Klyuchevskoi Volcano and a Model of Its Activity," Vulkanol. Seismol., No. 2, 3-42 (1988).

15. P. P. Firstov and A. V. Storcheus, "Acoustic Signals Accompanying Ejection of Klyuchevskoi Volcano on March-June, 1983," Vulkanol. Seismol., No. 5, 66-80 (1987).

16. P. P. Firstov and V. A. Shirokov, "Localization of the Roots of the Klyuchevskoi Group of Volcanoes as Inferred from Seismological Data," in Volcanism and the Earth's Interiors (Nauka, Moscow, 1971), pp. 113-117 [in Russian].

17. P. P. Firstov, Volcanic Acoustic Signals in a Range of $0.5-10 \mathrm{~Hz}$ in the Atmosphere and Their Relation with Explosive Processes (KamGPU, Petropavlovsk-Kamchatskii, 2003) [in Russian].

18. P. P. Firstov, V. V. Adushkin, and A. V. Storcheus, "Shock Air Waves Recorded during the September 1975 Great Tolbachik Fissure Eruption," Dokl. Akad. Nauk SSSR 259 (5), 1078-1081 (1978).

19. E. I. Gordeev, Yu. Yu. Mel'nikov, V. I. Sinitsyn, and V. N. Chebrov, "Volcanic Tremor of Klyuchevskoi Volcano (1984 Eruption of Summit Crater)," Vulkanol. Seismol., No. 5, 39-53 (1986).

20. V. I. Gorel'chik, "Seismic Manifestations of Volcanic Activity," in Deep Structure and Modern Activity of the Klyuchevskoi Group of Volcanoes (Vladivostok, 1976), pp. 108-118 [in Russian].

21. G. S. Gorshkov, "On the Localization Depth of the Magmatic Source of Klyuchevskoi Volcano," Dokl. Akad. Nauk SSSR 106 (4), 703-705 (1956).

22. C. Jaupart, "Magma Ascent at Shallow Levels," in Encyclopedia of Volcanoes (Academic Press, San Diego-Toronto, 2000), pp. 237-245.

23. A. P. Khrenov, T. M. Makhanova, O. A. Bogatikov, and A. N. Plate, "Results of Aerocosmic Studies of Kamchatkan Volcanoes (Klyuchevskoi Group Volcanoes)," Vulkanol. Seismol., No. 2, 3-20 (2002).

24. I. F. Kobylkin, V. V. Selivanov, V. S. Solov'ev, and N. N. Sysoev, Shock and Denotation Waves. Methods of Study (FIZMATLIT, Moscow, 2004) [in Russian].

25. A. S. Konov and A. Yu. Ozerov, "Relations and Trends in the Eruptions Dynamics of Klyuchevskoi Volcano and Associated Volcanic Tremor," Vulkanol. Seismol., No. 3, 21-38 (1988).
26. B. K. Kozlov, "Regimes and Forms of Movement of AirWater Mixture in the Vertical Pipe," in Hydrodynamics and Heat Exchange during Boiling in the High-Pressure Boiler (AN SSSR, Moscow, 1955), pp. 7-18.

27. S. S. Kutateladze and V. E. Nakoryakov, Heat Mass Exchange and Waves in the Gas-Liquid Systems (Nauka, Novosibirsk, 1984) [in Russian].

28. L. D. Landau and E. M. Lifshits, Mechanics of Continuous Media (Gostekhizdat, Moscow, 1944) [in Russian].

29. J. M. Lees, N. Symons, O. Chubarova, et al., "Tomographic Images of Klyuchevskoy Volcano $P$-Wave Velocity," in Volcanism and Subduction: The Kamchatka Region, Geophys. Monogr. Ser. 172, 293-302 (2007).

30. I. V. Luchitskii, Principles of Paleovolcanology. Volume 1. Modern Volcanoes (Nauka, Moscow, 1971) [in Russian].

31. G. A. Macdonald, Volcanoes (Prentice-Hall. Inc., Englewood Cliffs, New Jersey, 1972).

32. M. Manga and H. A. Stone, "Interactions between Bubbles in Magmas and Lavas: Effects of Deformation," J. Volcanol. Geotherm. Res. 63, 267-279 (1994).

33. M. Manga, "Waves of Bubbles in Magmatic Systems and Lavas," J. Geophys. Res. 101 (B8), 17.457-17.465 (1996).

34. A. Yu. Namiot, Gas Solubility in Water (Nedra, Moscow, 1991) [in Russian].

35. A. Yu. Ozerov and A. S. Konov, "Regularities in the Dynamics of the Klyuchevskoy Volcano Eruption," in Proceedings of Kagoshima International Conference on Volcanoes, Japan, 1988 (1988), p. 63-65.

36. A. Yu. Ozerov, "Experimental Complex for Modeling Basaltic Explosions," in Proceedings of Annual Conference Devoted to the Volcanology Day (March 28-31, 2007) (Petropavlovsk-Kamchatskii, 2007), pp. 144-156 [in Russian].

37. A. Yu. Ozerov, "The Evolution of High-Alumina Basalts of the Klyuchevskoy Volcano, Kamchatka, Russia, Based on Microprobe Analyses of Mineral Inclusions," J. Volcanol. Geotherm. Res, No. 95, 65-79 (2000).

38. A. Yu. Ozerov, A. A. Ariskin, Ph. Kyle, et al., "Petrological-Geochemical Model for Genetic Relationships between Basaltic and Andesitic Magmatism of Klyuchevskoi and Bezymyannyi Volcanoes, Kamchatka," Petrologiya 5 (6), 614-635 (1997) [Petrology 5, 55-569 (1997)].

39. A. Yu. Ozerov, A. A. Ariskin, and G. S. Barmina, "The Problem of Genetic Relations between High-Aluminous and High-Magnesian Basalts of the Klyuchevskoi Volcano, Kamchatka," Dokl. Akad. Nauk 350 (1), 104-107 (1996) [Dokl. Earth Sci. 350, 1127-1130 (1996)].

40. A. Yu. Ozerov, P. P. Firstov, and V. A. Gavrilov, "Periodicities in the Dynamics of Eruptions of Klyuchevskoy Volcano, Kamchatka," in Volcanism and Subduction: The Kamchatka Region, Geophys. Monograph. Series 172, 283-291 (2007).

41. A. Yu. Ozerov, "Periodicities in the Dynamics of the Colcanic Eruptions in Kamchatka, in 32nd International Geological Congress, Florence, Italy, 2004 (Florence, 2004), pp. 614.

42. Polytechnic Glossary (Izd-vo Sovetskaya Entsiklopediya, Moscow, 1976), p. 608 [in Russian]. 
43. E. Privitera, T. Sgroi, and S. Gresta, "Statistical Analysis of Intermittent Volcanic Tremor Associated with the September 1989 Summit Explosive Eruptions at Mount Etna, Sicily," J. Volcanol. Geotherm. Res 120, 235-247 (2003).

44. A. Rittmann, Vulkane und Ihre Tatigkeit (Ferdinand Enke Verlag, Stuttgart, 1960), p. 336.

45. V. A. Sakharov and M. A. Mokhov, Hydrodynamics of Gas-Liquid Mixtures in the Vertical Pipes and in the Production Lift (Izd-vo Neft' i gaz, Moscow, 2004) [in Russian].

46. L. I. Sedov, Similarity and Dimensional Methods in Mechanics, (10th ed., Nauka, Moscow, 1987; Academic Press, New York, 1959).

47. Yu. L. Sorokin, "On Conditions of Stability of Some regimes of Gas-Liquid Mixtures in Vertical Pipes," Prikl. Mekh. Teor. Fiz., No. 6, 160-165 (1963).

48. R. S. J. Sparks, "The Dynamics of Bubble Formation and Growth in Magmas: A Review and Analysis," J. Volcanol. Geotherm. Res 3, 1-37 (1978).
49. A. V. Storcheus and B. I. Samoilenko, "Study of Volcanic Explosions of the Tolbachik Eruption: Using Filming," Vulkanol. Seismol., No. 5, 102-106 (1983).

50. V. K. Utnasin, A. I. Abdurakhmanov, G. I. Anosov, et al., "Types of Magma Foci of Island Arc Volcanoes and Their Study by the Method of Deep Seismic Sounding of Kamchatka," in Volcanoes and Tectonosphere, (Tokai University Press, 1976), pp. 123-137.

51. S. Vergniolle and C. Jaupart, "Separated Two-Phase Flow and Basaltic Eruptions," J. Geophys. Res. 91, 12842-12860 (1986).

52. S. Vergniolle and C. Jaupart, "The Dynamics of Degassing at Kilauea Volcano, Hawaii," J. Geophys. Res, 95, 2793-2809 (1990).

53. S. Vergniolle and M. Mangan, "Hawaiian and Strombolian Eruptions," in Encyclopedia of Volcanoes (Academic, San Diego-Toronto, 2000), pp. 447-461.

54. V. I. Vlodavets, A Guidebook on Volcanology (Nauka, Moscow, 1984) [in Russian].

55. Graham B. Wallis, One-Dimensional Two-Phase Flow. (New York-Panama. McGraw-Hill Book Company, 1969). 